\title{
UM EXEMPLO DE “OLD MONEY” NO PARANÁ: A FAMÍLIA ROCHA LOURES ${ }^{1}$
}

\author{
Ana Crhistina Vanali ${ }^{2}$ \\ Katiano Miguel Cruz ${ }^{3}$
}

- Enviado em 11/03/2016

- Aprovado em 05/06/2016

\section{RESUMO}

A família Rocha Loures, com grande circulação entre as elites dominantes desde o século XVII, alia poder econômico ao poder político. Um dos membros da família obteve maior destaque e influência política: Rodrigo Costa da Rocha Loures, empresário do ramo de alimentos e fundador da Nutrimental. O artigo busca analisar importância da família Rocha Loures para a economia e a política paranaense.

Palavras-chave: Rocha Loures. Nutrimental. Família e economia. Empresas paranaenses.

\section{INTRODUÇÃO}

Até os anos de 1960 os estudos sobre família a consideravam como uma categoria resultante dos processos biológicos. Nos anos de 1970 temos a crise dos paradigmas de estudos sobre família e conceitos como "família nuclear" são criticados à luz de "unidade social primária", surgindo a necessidade de associar diferentes categorias de análise nos estudos sobre família. Entre os anos de 1980 e 1990 emergem novos estudos mostrando as diferentes redes que atualizam os laços familiares, não mais centrados apenas nos aspectos biológicos. Mesmo assim a família ainda continua sendo o ícone da tradição, sinônimo de estabilidade, de caráter privado. Do outro lado temos outra instituição, a empresa, de caráter público, isenta dos embaraços domésticos, um lugar dinâmico. Ainda faltam estudos, na área das Ciências Sociais da relação entre família e empresa,

\footnotetext{
${ }^{1}$ Artigo apresentado à disciplina HSO756 - Tópicos especiais em Sociologia Política II, ministrada pelo Prof. Dr. Ricardo Costa de Oliveira no segundo semestre de 2015.

${ }^{2}$ Doutoranda do Programa de Pós-graduação em Sociologia da UFPR. Endereço eletrônico: anacvanali @ yahoo.com.br

${ }^{3}$ Graduado em Administração pela Pontifícia Universidade Católica do Paraná, Especialista em Sociologia Política pela Universidade Federal do Paraná. Endereço eletrônico: katianomc@ yahoo.com.br
} 
mas podemos citar como porta de entrada a noção de composição e sentido das elites de Cohen (1981), o jogo de relações e distinções que sugere Bourdieu (1980), sobre as elites norte-americanas de Marcus (1992), sobre as elites brasileiras analisadas por Piscitelli (1999) ou sobre as elites italianas de Yanagisako (1991). Talvez a maior dificuldade metodológica na pesquisa da história de famílias é escrever sobre um grupo dominante contemporâneo, que pesquisa e publica histórias sobre si mesmo, além da superação da ideia de que haveria uma incompatibilidade entre empresa e família, entre racionalidade econômica e solidariedade familiar.

A relação empresa e família favorece a constituição de um patrimônio comum não apenas econômico, mas simbólico associado ao prestígio e às posições sociais. O patrimônio familiar - um nome de família, antepassados, uma história, uma rede de empresas - é o resultado de uma constituição e permite aos grupos marcarem sua distinção com relação aos demais grupos sociais. A empresa escolhida para análise foi a Nutrimental por ser da família Rocha Loures, uma família tradicional do Paraná. A empresa em si é jovem, está apenas na segunda geração no comando, mas a família é histórica e sua trajetória chega a se confundir com a história do Paraná.

\section{GENEALOGIA DA FAMÍLIA ROCHA LOURES}

A genealogia da família Rocha Loures ${ }^{4}$ já foi realizada por Negrão (1928), Pieruccini (1995), Teixeira (2009), Romaguera Netto (1992) e Oliveira (2001, 2007 e 2012). Iremos aqui apenas sistematizar os dados desses autores para o entendimento da genealogia dos atuais dirigentes da empresa Nutrimental: Rodrigo Costa e Rodrigo Santos, pai e filho respectivamente.

A figura central na reconstituição da genealogia da família Rocha Loures é Antonio Ferreira da Rocha Loures ${ }^{5}$, que participou no início do século XIX da Real Expedição da Conquista de Guarapuava que visava a abertura do caminho entre Curitiba e Guarapuava. Antonio trabalhou ao

\footnotetext{
4 “A origem do sobrenome Rocha Loures data do início do século XVIII quando veio para o Brasil, procedente da cidade portuguesa de Loures, o capitão Antonio João da Costa que se casou com Maria da Rocha de Jesus. Desta união nascera um varão, em cujo nome o pai agregaria em homenagem à terra distante, ficando seu nome João da Rocha Loures". (PIERUCCINI, 1995, p. 3)

5 Antonio da Rocha Loures nasceu em 03.04.1781 em São José dos Pinhais e faleceu em 20.02.1849, em Guarapuava (TEIXEIRA, 2009). Para Pieruccini (1995) o ano de nascimento de Antonio é 1782. Não localizamos a documentação que pudesse resolver essa discordância.
} 
lado de Diogo Pinto de Azevedo Portugal e de Padre Francisco das Chagas (do qual era parente pelo tronco de Balthazar Carrasco dos Reis) nessa empreitada (TAKATUZI, 2014). A linhagem de Antonio remonta aos clãs patriarcais fundadores de Curitiba. Pelo lado paterno era neto de Balthazar Carrasco dos Reis e filho de Gaspar Carrasco dos Reis. Pelo lado materno era neto de Mateus Leme e filho de Maria Leme da Silva. Antonio teve sete filhos, dos quais dois eram homens: Francisco Ferreira da Rocha Loures ${ }^{6}$ e João Cipriano Ferreira da Rocha Loures. Ambos foram, assim como o pai, sertanistas dedicados as expedições e aberturas de caminhos na primeira metade do século XIX e de colonização do território.

Dos sete filhos do casal Antonio Ferreira da Rocha Loures e Joana Maria de Lima, a filha mais velha, Maria Francisca da Rocha é a ascendente do fundador da empresa Nutrimental (Rodrigo Costa Rocha Loures). Maria Francisca casou com o capitão João Carvalho de Assumpção. Tiveram quatro filhos, entre eles Gertrudes Maria da Assumpção que casou com Francisco Antonio Alves da Rocha. Gertrudes e Francisco tiveram doze filhos. Seu nono filho foi Jesuíno Alves da Rocha Loures, avô do fundador da Nutrimental. Jesuíno casou com Francisca Ferreira da Siqueira ${ }^{7}$ e tiveram nove filhos, entre eles João Alves da Rocha Loures (1900-1986), pai do fundador da Nutrimental. Em 21 de setembro de 1929 João Alves casou com Rachel Faria Affonso da Costa (1909-2006). Tiveram nove filhos. O sexto filho é Rodrigo Costa da Rocha Loures, fundador da Nutrimental. Rodrigo Costa nasceu em Curitiba a $1^{\circ}$ de julho de 1943. Aos cinco dias de janeiro de 1966 casou com Vera Lilia Santos, nascida em Curitiba a 3 de maio de 1946. Rodrigo Costa e Vera tiveram três filhos. O mais velho é Rodrigo Santos da Rocha Loures, nascido em Curitiba em 13 de novembro de 1966. Rodrigo Santos é casado com Karin Peter ${ }^{8}$ e pai de dois filhos - Mayra e Dyego (PIERUCCINI, 1995; TEIXEIRA, 2009).

\footnotetext{
${ }^{6}$ Interessante consultar a obra de Thomé (2002) que fala da passagem de Francisco Ferreira da Rocha Loures pela Região do Contestado na década de 1840.

${ }^{7}$ Filha de João Ferreira dos Santos e Maximiliana Siqueira Cortes (TEIXEIRA, 2009).

${ }^{8}$ Pieruccini (1995) aponta que em 30 de setembro de 1995 Rodrigo Santos da Rocha Loures havia casado com Letícia Almada da Silva e não apresentava descendência. Em 2015, pelas redes sociais, Rodrigo Santos aparece como sendo casado com Karin Peter. Não conseguimos localizar documentação que indique se o casamento com Karin é em segunda núpcias. Consultar http://www.webwiki.pt/rodrigo-rocha. http://www.paranaonline.com.br/colunistas/diplomacia/26200/PARANA+E+COREIA+MAIS+PROXIMOS.

http://jornalsolnascenteassai.blogspot.com.br/2013/09/rodrigo-rocha-loures-recebe-homenagem.html. http://haraspp.com.br/noticia_1etapashpr.php. Todos os sítios foram acessados em 28.jan.2016.
} 


\section{ÁRVORE GENEALÓGICA DE RODRIGO COSTA DA ROCHA LOURES}

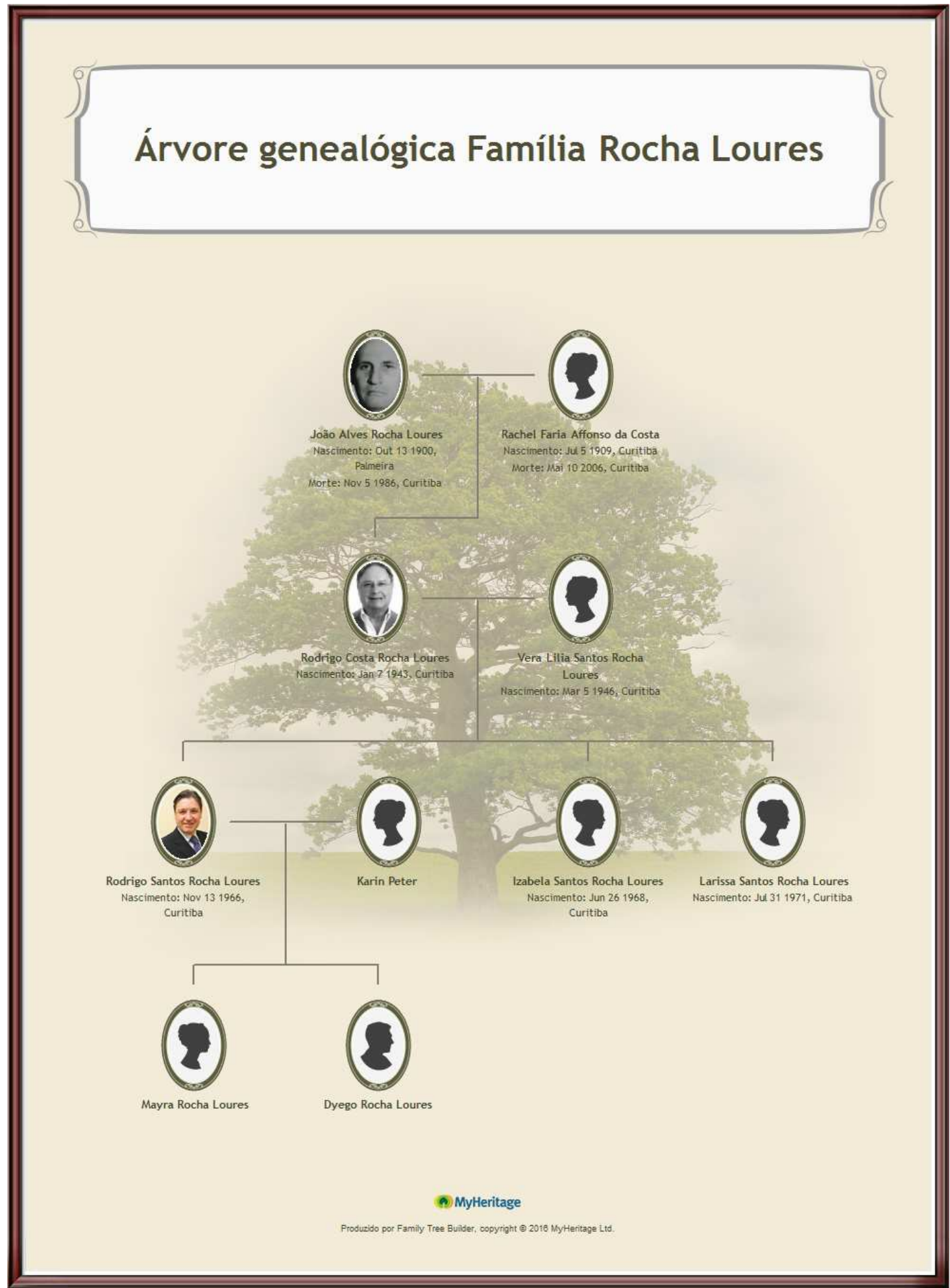

Elaboração dos autores 
Pelo exposto acima podemos perceber que a genealogia da família Rocha Loures é marcada pelo lado paterno como descendentes dos clãs patriarcas fundadores de Curitiba: Carrasco do Reis e Mateus Leme que constituíam a elite de sua época e cujos descendentes seriam figuras públicas de destaque na sociedade paranaense. Pelo lado materno, Rachel Faria era neta do Presidente Faria (que foi duas vezes presidente da Província do Paraná) e descendente de Lourenço Pinto de Sá Ribas (deputado pela $5^{\text {a }}$ Comarca na Assembleia Provincial Paulista e presidente da Câmara de Curitiba). Era tataraneta de Lourenço Ribeiro de Andrade (capitão-mor de Curitiba) e filha de Didio Costa (oficial da Marinha de Guerra Brasileira, intelectual renomado, deputado estadual no Congresso Legislativo Paranaense e prefeito de Paranaguá destituído pela Revolução de 30).

Ao final do século XIX os membros da família Rocha Loures tornam-se grandes proprietários de terras na região campeira, pois com a abertura dos caminhos de Guarapuava, Palmas e Missões, o tropeirismo e o fornecimento de campos de invernagem para as tropas era um negócio altamente lucrativo. Assim, ao lado do poder econômico que conquistaram, começam a aliar o poder político fornecendo diversas lideranças políticas regionais. Um exemplo é João Ferreira dos Santos, maragato, que foi morto durante a Revolução Federalista e era o sogro de Jesuíno Alves da Rocha Loures, que assume as responsabilidades da família após a sua morte (PIERUCCINI, 1995). Jesuíno, após a morte do sogro, tenta diversificar os negócios da família, mas não foi bem-sucedido e acabou empobrecendo. Para recuperar a condição econômica da família ele percebe a necessidade de transformação do estilo de vida que o início do século XX impunha. Então, a exemplo de seus sobrinhos Affonso e Marins Alves de Camargo ${ }^{9}$ que haviam saído de Guarapuava para estudar Direito em São Paulo rompendo com a tradição de fazendeiros da família e indo atrás de títulos de bacharéis, Jesuíno decide fazer o mesmo com os filhos Silvano, Annibal, João e Josino, que se formam em Agronomia, Medicina, Direito e Medicina, respectivamente. Durante o período da Primeira República (1889-1930), apesar da família Rocha Loures estar em recuperação financeira, ela já integrava a oligarquia dominante do Estado do Paraná via relações de parentesco, podendo-se perceber a prática do nepotismo através da boa colocação profissional, em

\footnotetext{
${ }^{9}$ Filhos de Pedro Alves de Camargo e de Francisca de Camargo (TEIXEIRA, 2009).
} 
altos cargos de relevo na administração pública, de alguns membros da família Rocha Loures ou de seus familiares, parentes ${ }^{10}$.

Até a década de 1980 a família Rocha Loures tem mais destaque no interior do Paraná com seus membros assumindo funções de juiz, desembargador, professor universitário, proprietários do primeiro jornal impresso da cidade de Londrina. Após a década de oitenta, a família Rocha Loures mudou seu foco para a capital do Estado do Paraná, tendo com principais expoentes Rodrigo e Rodriguinho da Rocha Loures (filho e neto de João de Alves da Rocha Loures, respectivamente). A parte da família que permaneceu em Londrina exerce principalmente atividades de tabelionato (Cartório Salinet e Cartório Rocha, por exemplo) (SILVA, 2015a).

Abaixo segue uma síntese de membros da família Rocha Loures que atuaram na vida pública e política ${ }^{11}$ :

- FRANCISCO FERREIRA DA ROCHA LOURES (1808-1871): deputado na Assembleia Provincial do Paraná no biênio 1862/1863 (NICOLAS, 1984).

- SYLVANO ALVES DA ROCHA LOURES (1893-1979): foi eleito deputado estadual para o biênio 1930/31, mas não chegou a exercer o mandato pois foi deposto pela Revolução de 30 (NICOLAS, 1984). Atuou como engenheiro da Secretaria de Obras Públicas do Paraná, Delegado Seccional do Recenseamento, professor da Escola Agronômica do Paraná, inspetor de Vigilância Sanitária no Porto de Paranaguá, representante do Ministério da Agricultura, presidente da

10 “O poderio da família Rocha Loures rendeu também aos seus membros uma rede de cartórios espalhados pelo Norte e Oeste do Estado do Paraná, com tabelionato em Maringá, $2^{\circ}$ Tabelionato de Notas, tendo como atual tabelião Diderot Augusto Araujo da Rocha Loures e em Santa Mariana, Tabelionato de Notas e Protesto de Títulos, sob a responsabilidade de Anibal Alves da Rocha Loures Sobrinho, ambos sobrinhos-netos de João Alves da Rocha Loures (filhos de seu irmão Euclides Rocha Loures com Maria Rosa da Silva). Os dois filhos de Annibal Rocha Loures, também irmão de João, foram serventuários da justiça, assim como Francisco Alves da Rocha Loures, irmão de João, e dois de seus filhos (Paulo e Ruy) também o são. Outro sobrinho de João Alves, filho de sua irmã Maria Alves da Rocha Loures com Cypriano Miranda Salinet, também era tabelião em Londrina, função e propriedade "herdada" por seu filho Francisco Loures Salinet Junior, do $4^{\circ}$ Tabelionato de Notas de Londrina; outro filho do mesmo casal, Jesuíno Loures Salinet era tabelião em Jataizinho, próximo à Londrina, no Cartório de Registro Civil e Tabelionato de Notas "herdado" também por seu filho, atual tabelião, Marcelo Loures Salinet. A relação dos Loures Salinet com os cartórios se estende até o Oeste do Estado, pois Fernando Loures Salinet, também filho de Maria Alves e Cypriano era tabelião em Foz do Iguaçu, função atualmente exercida pelo filho Fernando Loures Salinet Filho, no $1^{\mathrm{o}}$ Tabelionato de Notas e Protestos de Títulos de Foz do Iguaçu". (SILVA, 2015a, p.165-166)

${ }^{11}$ Segundo spitio http://www.museumaconicoparanaense.com/MMPRaiz/LojaPRate1973/0237_obreiros.htm acessado em 27.fev.2016 a Família Rocha Loures tem relações com a Maçonaria, mas esse é um estudo a ser realizado. 
Comissão de Eficiência do Ministério Agrícola, além de vasta atuação em órgãos da área florestal e de organização de classe dos engenheiros agrônomos ${ }^{12}$.

- ANNIBAL ALVES DA ROCHA LOURES (1898-1961): foi prefeito da Colônia Mineira, atual cidade de Siqueira Campos (1928), mas não chega a finalizar o mandato por "falta de vocação política, pois candidatou-se porque os primos Affonso e Marins Camargo insistiram" (PIERUCCINI, 1995, p.98) ${ }^{13}$.

- JOÃO ALVES DA ROCHA LOURES (1900-1986): suplente deputado federal pelo Paraná convocado para a $2^{\text {a }}$ legislatura (1952-1954) (NICOLAS, 1977). Havia sido candidato ao senado nas eleições de 1945, mas perdeu para Flávio Guimarães e Roberto Glasser. Nas eleições de 1950 candidatou-se ao cargo de Deputado Federal e não foi eleito ${ }^{14}$. No pleito de 1954 , desejava concorrer ao cargo de Senador, ao que foi impedido pelo amigo e marido da prima, o então governador Bento Munhoz. João decide levar sua candidatura para a convenção do PR, mas sem o apoio dos diretórios municipais acaba enfraquecido. Decide mudar de partido, filiando-se ao Partido Liberal e concorre ao Senado, perdendo o pleito. Esse fato o motivou nunca mais concorrer a nenhum cargo eletivo e a se afastar em definitivo na política. (SILVA, 2015a)

- JOSINO ALVES DA ROCHA LOURES (1910-1994): foi vereador em Joinville (1937), vereador em Londrina (1947, 1951), deputado federal (3ª legislatura 1955-1958). Nas eleições de 1958 não foi reeleito deputado federal então assume o cargo de Secretário de Estado do Trabalho e

\footnotetext{
${ }^{12}$ Disponível http://www.alep.pr.gov.br/. Acess0 14.fev.2016.

${ }^{13}$ Silva (2015a, p.158) na nota de rodapé 103 destaca que “...em 1960, Annibal se candidatou ao cargo de prefeito de Astorga, pelo PSD, pleito em que saiu vitorioso, tendo ocupado a função entre os anos de 1961 e 1964”. Porém, o Annibal que foi eleito prefeito de Astorga e exerceu o mandato até 1964 foi Aníbal Alves da Rocha Loures Sobrinho que nasceu em 1925 e faleceu em 2015. Annibal Alves da Rocha Loures, o tio, faleceu no ano de 1961, portanto se fosse ele o eleito, e não o sobrinho, não teria terminado o mandato em 1964 (Gazeta do Povo, 29 de maio de 2015. Lista de falecimentos - Aníbal Alves da Rocha Loures Sobrinho: da leitura dos cadernos de política à vida pública). Ver também http://astorga.pr.gov.br/prefeitos anteriores.php. Acesso 27.fev.2016.

${ }^{14} \mathrm{O}$ insucesso nesse pleito foi depositado no excesso de dedicação de João à campanha de Bento Munhoz da Rocha que era casado com sua prima Flora Camargo (filha de Affonso Camargo), deixando de cuidar da sua própria. (SILVA, 2015a)
} 
Assistência Social a convite do então governador Moysés Lupion (BATISTELLA, 2014; NICOLAS, 1977; SILVA, 2015; WENDLAND, 2011). Em 1951 afastou-se do cargo de vereador para assumir o cargo de confiança ofertado pelo marido de sua prima, o governador Bento Munhoz da Rocha Neto, estando à frente do Departamento de Assistência Técnica aos Municípios (SILVA, 2015a).

- RENATO LOURES BUENO (1925-2002): foi vereador em Londrina (1955-1959) ${ }^{15}$, deputado estadual em quatro legislaturas (1958, 1963, 1967 e 1978), deputado federal em uma legislatura (1983), candidato à prefeitura de Londrina sendo derrotado (1959) e Ministro Substituto do Tribunal de Contas do Paraná (1978) (GRANATO, 2013; SILVA, 2015). Na década de 1970 foi Diretor Clínico do Centro de Pesquisas Médicas e Secretário Municipal da Saúde e Assistência Social na Prefeitura Municipal de Cascavel. Em 1986 disputou novamente o cargo de deputado federal, ficando apenas na suplência, mas se consolidando como o membro da família Rocha Loures que obteve maior sucesso em eleições até o momento, embora tenha ficado longe de obter o mesmo prestígio que seu tio e sogro, João Alves da Rocha Loures (SILVA, 2015a).

- ANIBAL ALVES DA ROCHA LOURES SOBRINHO (1925-2015): prefeito de Astorga (19611964). Após esse mandato volta a trabalhar com cartório ${ }^{16}$.

- ANTONIO DA ROCHA LOURES ${ }^{17}$ : foi prefeito de Cerro Azul (1938-1939) ${ }^{18}$ e de Antonina (1941) (SILVA, 2015a).

\footnotetext{
${ }^{15}$ Renato elegeu-se vereador pelo PR com 426 votos, sendo o mais votado da coligação PSD-PR. A mesma sorte não teve o primo Ruy Loures Salinet, que obteve no mesmo pleito para vereador apenas 14 votos (SILVA, 2015a).

16 Disponível em http://www.gazetadopovo.com.br/servicos/falecimentos/anibal-alves-da-rocha-loures-sobrinho-daleitura-dos-cadernos-de-politica-a-vida-publica-19gvjuzwyy71r4afsglt8wmvg (29 de maio de 2015). Acesso em 27.fev.2015.
}

\footnotetext{
${ }^{17}$ Sobrinho de João Alves da Rocha Loures, filho de seu irmão Euclides. Primo de Rodrigo Costa da Rocha Loures.
} 
- GILDA POLI DA ROCHA LOURES: Secretária de Estado de Educação nos governos de José Richa, Álvaro Dias e de Roberto Requião (1986-1991), passando também pelo cargo de Secretária de Estado da Cultura (1991-1994), Diretora de Departamento da Imprensa Oficial do Paraná e Diretora da hoje Universidade Estadual do Paraná, com sede em Jacarezinho (RESENDE, 2014; SILVA 2015a).

- RODRIGO COSTA DA ROCHA LOURES ${ }^{19}$ (01.07.1943)

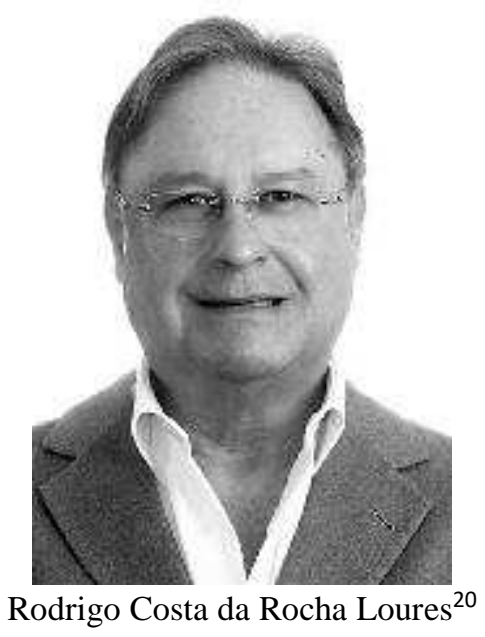

Formado em administração de empresas pela FGV. Foi professor de Administração na UFPR e na PUC-PR. Tem mais de 40 anos de história como empresário ${ }^{21}$ e mais de três décadas de

\footnotetext{
${ }^{18}$ Disponível em http://www.cerroazul.pr.gov.br/dadosgerais. Acesso 27.fev.2016.

19 Conforme http://www.editoragente.com.br/autor/86/rodrigo-costa-da-rocha-loures. http://www.fiesp.com.br/noticias/perfil-rodrigo-costa-da-rocha-loures-presidente-do-conic-da-fiesp/. Acesso 14.fev.2016. Ver também Manfredini (2011).

${ }^{20}$ Fonte: http://www.eleicoes2012.info/rodrigo-rocha-loures/. Acesso 10.jan.2016.

${ }^{21}$ Segundo sítio http://bpwbrasil.org/new/?p=259, acesso 12.fev.2016, Rodrigo Costa da Rocha Loures teria iniciado sua vida empresarial em Londrina, na agropecuária, mas não encontramos mais informações sobre esse tema.
} 
atuação na representação institucional do setor alimentício, conforme alguns exemplos que destacamos abaixo:22

- presidente da Associação Brasileira da Indústria da Nutrição (ABIN)

- vice-presidente da Associação Brasileira das Indústrias da Alimentação (ABIA)

- presidente do Conselho Superior de Inovação e Competitividade (CONICA) da Federação das Indústrias do Estado de São Paulo (FIESP)

- presidente do Conselho Deliberativo do Instituto Brasileiro Qualidade e Produto (IBQP)

- presidente Conselho de Inovação e Competitividade da Federação das Indústrias do Estado do Paraná (FIEP)

- vice-presidente da Confederação Nacional das Indústrias (CNI), onde também presidiu por quatro anos o Conselho de Política Industrial e Desenvolvimento Tecnológico (COPIN)

- membro do Conselho de Economia

- integrante o Conselho de Desenvolvimento Econômico e Social (CDES) da Presidência da República e o Conselho Diretor do Fundo Nacional de Desenvolvimento Científico e Tecnológico (FNDCT)

É atuante na questão da sustentabilidade desde 1992. Destacamos algumas de suas participações como representante institucional nessa área: ${ }^{23}$

- um dos 20 fundadores da Fundação Brasileira do Desenvolvimento Sustentável (FBDS)

- membro Board do Comitê Brasileiro do Global Compact da ONU e coordenador do Global Fórum da América Latina (desde 2003)

- membro secretaria executiva do Movimento Nacional pela Cidadania e Solidariedade

- autor dos livros "Educar e Inovar na Sustentabilidade", "Sustentabilidade XXI: Educar e Inovar sob uma Nova Consciência" e "Sustentabilidade Revisitada"

22 Disponível em http://www.fiesp.com.br/noticias/perfil-rodrigo-costa-da-rocha-loures-presidente-do-conic-da-fiesp/. Acesso em 12.fev.2016.

23 Disponível http://www.fiesp.com.br/noticias/perfil-rodrigo-costa-da-rocha-loures-presidente-do-conic-da-fiesp/. Acesso 12.fev.2016. 
Foi presidente da Federação das Indústrias do Paraná (FIEP) de 2003 a 2011. Sua primeira gestão (2003-2007) foi marcada pela implantação de um modelo de gestão profissional e eficiente e por investimentos na ampliação e modernização da infra-estrutura. Nesses primeiros quatro anos à frente da FIEP, levou a indústria paranaense a participar de fóruns estratégicos nacionais. Também se destacou na mobilização do empresariado em prol do desenvolvimento do Estado e do país. Idealizou os dois Congressos Paranaenses da Indústria realizados em 2004 e em 2006, reunindo cerca de 3 mil participantes de todos os segmentos industriais e regiões do Paraná. Foi o criador e coordenador dos dois Congressos Brasileiros de Inovação na Indústria, promovidos pela CNI em 2005 e 2007, em São Paulo, que resultaram em proposta de aprofundamento da política industrial e desenvolvimento tecnológico para o Brasil em encaminhamento à presidência da República. Em 2010 articulou empresários na construção de uma Proposta de Política Industrial para o Paraná e mobilizou a bancada federal paranaense na defesa, junto ao governo federal, de uma pauta de investimentos estratégicos para propiciar o desenvolvimento econômico do Estado. ${ }^{24}$

Também, durante esse período em que foi presidente da FIEP, Rodrigo Costa foi indiciado pelo TCU por supostas irregularidades cometidos tanto na sua gestão, como na gestão do presidente anterior José Carlos Gomes Carvalho (o Carvalhinho). Entre esses indícios de fraudes estão:

... entre elas despesas amparadas em documentos inidôneos; despesas que teriam beneficiado funcionários das entidades sem comprovação da prestação de serviços; repasse de R\$ 265 mil e R\$ 561 mil ao Instituto Paraná de Desenvolvimento (IPR), presidido por Rodrigo da Rocha Loures, sem qualquer comprovação de despesas; ressarcimento de despesas pessoais da filha de Rodrigo Rocha Loures, Larissa, tais como faturas telefônicas, restaurante, táxi; diversos pagamentos à empresa LWL Comunicações, de propriedade de Luiz Henrique Weber e Luciana Rocha Loures, sobrinha de Rodrigo; despesas com viagens para Cleveland para Luciana, sem comprovação de despesas ou justificativas; pagamento de passagens aéreas com destino ao Canadá para Dídio Costa Rocha Loures, irmão de Rodrigo, entre outras, o TCU autorizou a audiência de Rodrigo Rocha Loures a respeito; de Marcos Müeller Schlemm, diretor-superintendente do Sesi-PR; Ubiratan de Lara, exdiretor-regional do Senai-PR; Carlos Sérgio Asinelli, diretor-regional do Senai-PR; Helena Gid Abage, ex-diretora-superintendente-adjunta do IEL/PR e Gina Gulineli Paladino, diretora-executiva do IEL/PR. Todos eles poderão apresentar justificativas para as supostas irregularidades. ${ }^{25}$

\footnotetext{
${ }^{24}$ Disponível http://www.fiepr.org.br/. Acesso 12.fev.2016.
}

25 SAIKI, Lyrian (2005). TCU determina devolução de R\$ 36 milhões ao Sesi/Senai. Disponível em http://www.parana-online.com.br/editoria/economia/news/143049/07/outubro/2005. Acesso em 28.fev.2016. É necessário realizar uma consulta junta aos arquivos do TCU para saber o parecer final desse processo contra os expresidentes da FIEP José Carlos Gomes Carvalho e Rodrigo Costa da Rocha Loures mas devido ao tempo limitado para a elaboração desse artigo não foi possível realizar a consulta neste primeiro momento. 
Em 2012 tenda ingressar na carreira política sendo candidato à prefeitura de São José dos Pinhais pela coligação São José - a cidade que sonhamos (PV-PMDB). Obteve mais de 26\% dos votos. E um dos prováveis candidatos à prefeitura de São José dos Pinhais nas eleições municipais de 2016.

A trajetória de líder empresarial, figura política e outros aspectos da vida de Rodrigo Costa da Rocha Loures (como sua produção bibliográfica) ainda estão para ser estudados. Além de empresário, ele tem várias participações como conferencista em eventos nacionais e internacionais, é coautor de vários livros relativos a desenvolvimento e sustentabilidade, artigos publicados em jornais e revistas do país e desde 2006 é articulista permanente do jornal Gazeta Mercantil e atualmente escreve no jornal Brasil Econômico, além de ser membro do Comité Executivo da Nutrimental. Atualmente é presidente da Nutrimental, presidente do Conselho de Inovação e Competitividade da FIESP e presidente do Diretório Municipal do PMDB em São José dos Pinhais $^{26}$. Em 2 de junho de 2016 teve seu nome indicado para assumir a direção geral da Usina de Itaipu em substituição a Jorge Samek que está no cargo desde 2003 (primeiro governo Lula). Segundo Oliveira $(2016)^{27}$ :

A indicação de Rodrigo Rocha Loures, o pai, para a diretoria-geral da Itaipu revela a força política de nomes da classe dominante tradicional paranaense, do antigo núcleo duro da Genealogia Paranaense (IV, 211), no golpe político em andamento. Esta é uma família com trezentos anos de poder social em Curitiba. As conexões do filho Rodrigo Rocha Loures, ex-deputado federal e assessor de gabinete de Temer, foram decisivas para derrotar indicações de outras famílias políticas regionais bem mais recentes, como Lupion e Richa ${ }^{28}$

A nomeação no Diário Oficial ainda não havia ocorrido quando da finalização desse artigo. ${ }^{29}$

\footnotetext{
${ }^{26}$ Disponível em http://www.fiesp.com.br/noticias/conselho-superior-de-inovacao-e-competitividade-da-fiesp-discuteestrutura-de-estimulo-a-pesquisa/ e http://www.tse.jus.br/sadJudSGIP/dadosCompletosOrgaoPartidarioAction.do. Acesso 21.maio.2016

27 Verificar http://www.bemparana.com.br/politicaemdebate/index.php/2016/06/02/ex-presidente-de-fiep-rocha-louresdeve-comandar-itaipu/. Acesso em 04.junho.2016.
}

\footnotetext{
${ }^{28}$ Entrevista cedida à Ana Vanali em 04.06.2016. Na citação, quando o entrevistado indica à Genealogia Paranaense a referência é a obra de Francisco Negrão, Genealogia Paranaense, volume 4, editado em Curitiba no ano de 1928.
}

29 Gazeta do Povo de 04 de junho de 2016. Com indicação de Rocha Loures, paranaenses mantêm “feudo" em Itaipu: e nove diretores-gerais brasileiros na história da companhia, sete são paranaenses ou radicados no Paraná 


\section{- RODRIGO SANTOS DA ROCHA LOURES (Rodriguinho) ${ }^{\mathbf{3 0}}(13.11 .1966)$}

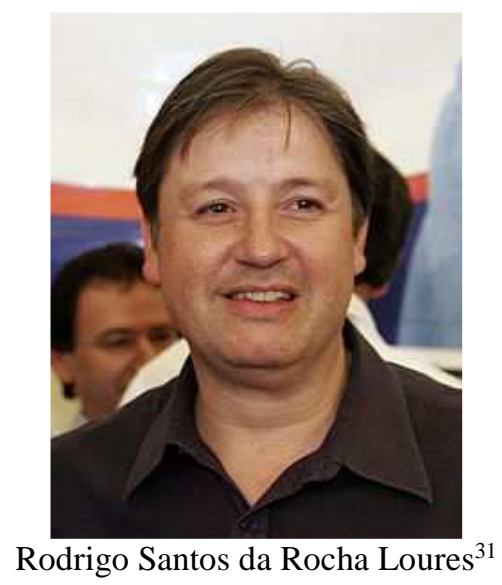

Formado em Administração de Empresas. Desde o final da década de 1990 ocupa um cargo de direção na empresa da família. É atuante na área política pelo partido PMDB. Destacamos algumas de suas participações:

2003-2005: chefe de gabinete do governador Roberto Requião.

2005-2007: idealizador e coordenador das ações em favor dos objetivos do desenvolvimento do Milênio no Paraná através do Programa Nós Podemos Paraná.

2007-2011: deputado federal pelo Paraná. Foi vice-líder do bloco PMDB-PSC e PTC na Câmara dos Deputados ${ }^{32}$.

\footnotetext{
. Disponível em http://www.gazetadopovo.com.br/vida-publica/com-indicacao-de-rocha-loures-paranaenses-mantemfeudo-em-itaipu-5us7npxtsefgnx1ayr7kx3dy4. Acesso em 04.junho.2016.

Gazeta do Povo de 02 de junho de 2016. Rodrigo Rocha Loures será o diretor-geral de Itaipu

Nome de empresário, pai do ex-deputado federal Rodrigo Santos da Rocha Loures, será publicado nos próximos dias no Diário Oficial da União. Disponível em http://www.gazetadopovo.com.br/vida-publica/rodrigo-rocha-loures-sera-odiretor-geral-de-itaipu-6512fiwbvwdyoerm2wry1ict8. Acesso em 04.junho.2016.
}

30 Informações disponíveis em http://www.parana-online.com.br/editoria/policia/news/86509/; http://www.eleicoes2014.com.br/candidatos-pmdb-parana/; $\quad$ http://www.fiepr.org.br/nospodemosparana/curitiba--objetivo-7-1-2013-163599.shtml; http://pmdb.org.br/institucional/comissao-executiva-nacional/; http://pmdbpr.org.br/2015/10/chapa-pmdb-de-cara-limpa-e-eleita-com-98-7-dos-votos-na-convencao-do-pmdb-doparana/; http://pmdbpr.org.br/page/39/?view=article\&catid=37\%3Agoverno\&id=755\%3Arequiao-criara-lei-sobreaplicacao-em-bancos\&option=com_content\&Itemid=65. Todos acessado em 12.fev.2016.

31 Fonte http://veja.abril.com.br/blog/radar-on-line/governo/articulacao-em-curso-para-tornar-rocha-loures-ministro/. Acesso 12.fev.2016.

32 Segundo Oliveira (2007, p.163) "a análise entre poder, grandes interesses e parentesco fica explícita quando pesquisamos algumas das biografias dos atuais [2007] deputados federais. Dos 30 eleitos, 15 apresentaram patrimônios 
2010: candidato a vice-governador no Paraná na chapa encabeçadas por Osmar Dias na coligação A União faz um novo amanhã (PDT-PMDB-PT-PSC-PR-PC do B).

2011-2014: chefe de gabinete do vice-presidente Michel Temer.

2014: candidato a deputado federal pelo PMDB (apesar dos 58.493 votos não foi eleito pois perdeu pelo quociente de outros partidos ${ }^{33}$ ).

2015: chefe da Secretaria de Relações Institucionais (SRI) do vice-presidente da República, Michel Temer $^{34}$. Com a reforma administrativa, em setembro de 2015 acertou sua exoneração da assessoria especial da pasta SRI e foi reintegrado ao gabinete do vicepresidente.

Desde 13 de maio de 2016 é assessor especial do presidente interino Michel Temer ${ }^{35}$.

Rodriguinho já foi vice tesoureiro do diretório nacional do PMDB, tesoureiro do diretório estadual do PMDB-PR, membro da executiva nacional do PMDB como tesoureiro adjunto e ocupa atualmente a posição de membro nato, delegado titular e membro titular do Diretório Estadual do PMDB-PR e $1^{\circ}$ vogal da Executiva Estadual do PMDB-PR ${ }^{36}$ em chapa composta, dentre outros, pelo sobrinho de Roberto Requião, João Arruda Jr, atual secretário geral do Diretório do PMBD no Paraná (SILVA, 2015a). Ainda falta um estudo de sua trajetória política e empresarial.

Nessa rápida sistematização de dados sobre alguns dos membros da família Rocha Loures percebemos que as conexões e os capitais sociais e políticos são acumulados ao longo de diversas

milionários na Justiça Eleitoral, e a maioria possui algum tipo de vínculo com famílias históricas da classe dominante tradicional. Os que não apresentam antigas conexões com poderes tradicionais geralmente são representantes de novas fortunas, em novas atividades econômicas. Três deputados federais eleitos pelo Paraná estão na lista dos dez maiores gastadores do País na campanha eleitoral de 2006. .... O segundo colocado também é paranaense, o peemedebista Rocha Loures, com despesas totais de R \$ 2,92 milhões... O deputado federal reeleito Odilio Balbinotti (PMDB-PR) é o segundo eleito mais rico, com patrimônio declarado de $\mathrm{R} \$ 123,8$ milhões, tendo gasto $\mathrm{R} \$ 1,1$ milhão na própria campanha. Rodrigo Rocha Loures (PMDB-PR) autofinanciou-se com o valor declarado de R\$ 1,13 milhão".

${ }^{33}$ Disponível em http://www.eleicoes2014.com.br/rodrigo-rocha-loures/. Acesso 29.fevereiro.2016.

34 Disponível em http://www.artagaojunior.com.br/detalhe noticia/artagao-junior-recebe-chefe-de-relacoesinstitucionais-da-vice-presidencia-da-republica. Acesso em 20.maio.2016.

35 Disponível em http://www.esmaelmorais.com.br/2016/05/rocha-loures-cotado-para-itaipu/ e http://www.fabiocampana.com.br/2015/09/rocha-loures-pede-demissao-e-volta-ao-gabinete-de-temer/. Acesso em 29.maio.2016.

${ }^{36}$ Disponível em http://pmdbpr.org.br/. Acesso 29.abril.2016. 
gerações, como já demonstrou Oliveira (2001). Para Oliveira (2007, p.150) “no Brasil, a ação social e econômica dos poderosos fundamenta-se em torno do aparelho de Estado, como forma direta e indireta de controles do fluxo de informações, capitais e privilégios essenciais para a reprodução ampliada da classe dominante”. A família Rocha Loures é exemplo de uma intricada rede política, entendida aqui como uma conexão de interesses envolvendo empresários e cargos políticos no aparelho de Estado em diferentes poderes, no executivo, legislativo e no judiciário, e em outros espaços de poder em função de operações de mútuo benefício e ações político-financeiras articuladas na informalidade (OLIVEIRA, 2007). Exemplo elucidativo dessa rede política foram as relações da família governamental Requião com o empresário Rodrigo Rocha Loures, dono da empresa Nutrimental e Presidente da Federação das Empresas do Estado do Paraná (FIEP) de 2003 a 2011, uma das maiores lideranças empresariais do estado, e membro de uma tradicional família, com três séculos de poder político na região. Em 2003, Rocha Loures (o pai) contou com o apoio de Requião na sua eleição para Presidente da FIEP. Seu filho, Rodriguinho Rocha Loures, foi chefe de gabinete de Requião em 2003/4 e, eleito deputado federal pelo PMDB em 2006, e teve como chefe de gabinete o filho de Roberto Requião, Maurício (OLIVEIRA, 2007).

\section{GENUINAMENTE PARANAENSE}

Oferecer ao mercado alimentos saudáveis, por meio de uma contínua valorização do fator humano. Graças a essa conduta, a empresa tem espaço consolidado nos mercados em que atua, ancorada na confiança de seus colaboradores, clientes e fornecedores. ${ }^{37}$

A empresa Nutrimental S.A Indústria e Comércio de Alimentos é uma empresa paranaense que foi fundada em 23 de julho de 1968 por Rodrigo Rocha Loures e hoje, quase com meio século de atuação no mercado é uma das maiores empresas do setor alimentício do Brasil ${ }^{38}$. Sua fundação foi uma parceria que nasceu dentro dos departamentos de Engenharia Química e Administração da Universidade Federal do Paraná (UFPR). Rodrigo Rocha Loures, na época professor do curso de

\footnotetext{
${ }^{37}$ Filosofia da empresa Nutrimental. Disponível em http://www.nutrimental.com.br/. Acesso em 24.jan.2016.

${ }^{38}$ Sua produção corresponde a barras de cereais, farinhas infantis, refrescos, sobremesas, molhos, biscoitos, granolas e cereais matinais. Atuou também, com destaque, na área de merenda escolar até 1994. A empresa detém as marcas: Nutry, Nutrinho e Nutrilon. Disponível em http://www.nutrimental.com.br/. Acesso em 24.jan.2016.
} 
Administração da UFPR, passou a pesquisar a criação de um purê de batata instantâneo. Para viabilizar uma possível produção, instalou algumas máquinas num barracão de $200 \mathrm{~m}^{2}$ em uma antiga fazenda nas proximidades do Aeroporto Afonso Pena, em São José dos Pinhais.

... O pai, João Alves da Rocha Loures, o desejava administrador de suas fazendas no Norte do Paraná. Mas em São Paulo, no início dos anos 60, estudando na Escola de Administração da Fundação Getúlio Vargas, rendeu-se à atmosfera irresistivelmente industrial que enfeitiçava a juventude empreendedora. E foi embalado por essa inclinação que, de volta à Curitiba, o recém-formado Rodrigo Costa Rocha Loures foi trabalhar no escritório de consultoria e projetos industriais do irmão Dídio. Ali, poucos anos depois, conheceu Arthur Leme e Marcos Hauer, de quem se tornaria sócio para fundar, em 1968, a Nutrimental, pioneira das barras de cereais. Empreendimento nascido das pesquisas em tecnologias de alimentos da Universidade Federal do Paraná (UFPR), uma das pioneiras experiências de cooperação entre universidade e empresa no país. Hoje a empresa é líder no mercado nacional de barras de cereais e vice-líder no de cereais infantis. (MANFREDINI, 2011, p.10)

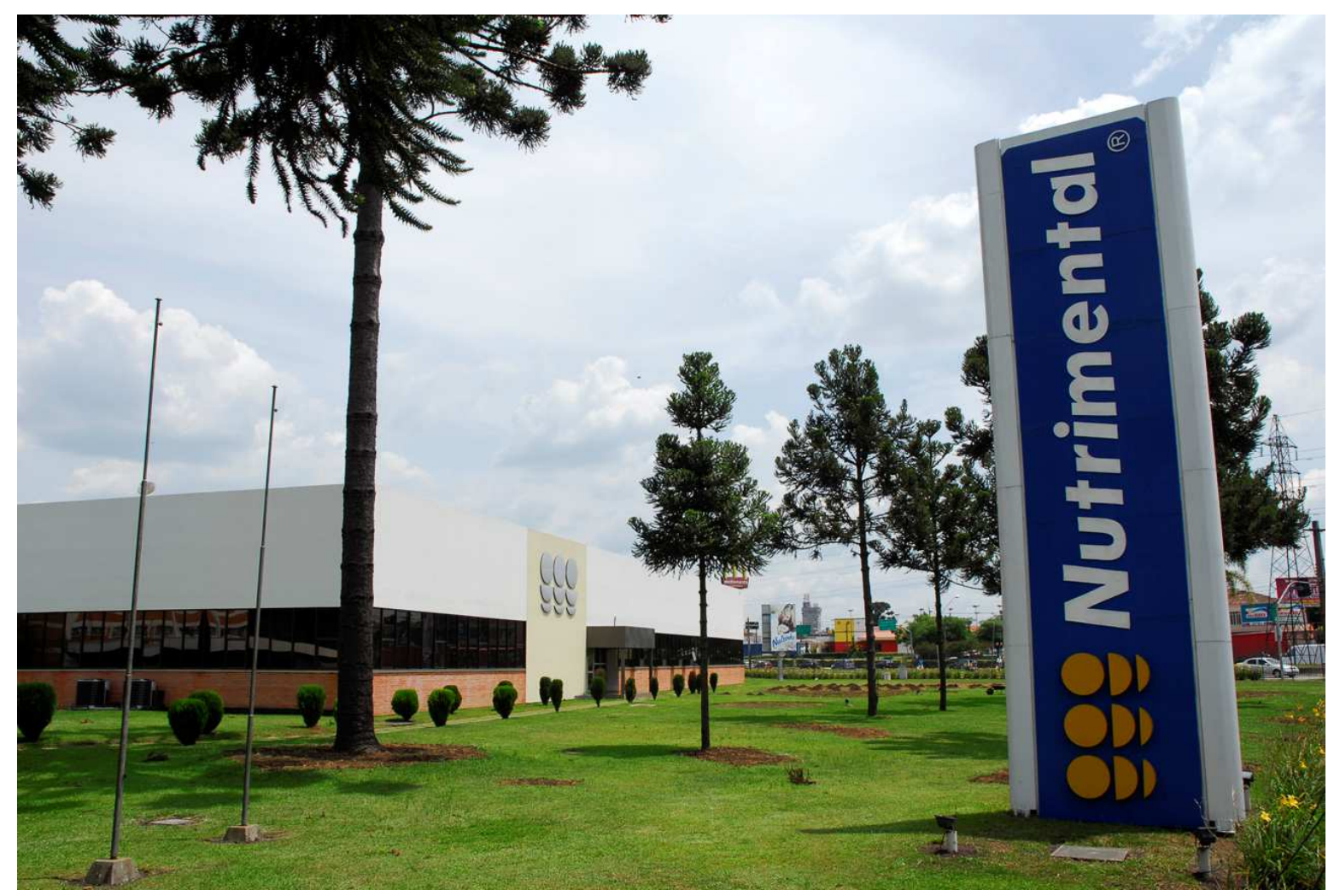

Fonte: http://www.nutrimental.com.br/. Acesso em 26.jan.2016 
Inicia suas atividades industriais com a fabricação de merenda escolar e fornecimento de alimentação para restaurantes industriais.

\begin{abstract}
"A Nutrimental é uma empresa de base tecnológica", diz Rodrigo Rocha Loures. Nasceu para desidratar batata e logo em seguida aproveitou essa tecnologia para desidratar feijão e produzir uma sopa que obteve grande sucesso na merenda escolar. Na época o governo brasileiro foi obrigado a dar conta da merenda, uma vez que os Estados Unidos deixaram de realizar as doações até então feitas. Daí para a frente, a Nutrimental seguiu um percurso de pioneirismo e inovação. (MANFREDINI, 2011, p.15)
\end{abstract}

Em 1975 é uma das empresas pioneiras no Brasil a desenvolver e fabricar proteína texturizada de soja. Em 1984 desenvolve a alimentação balanceada para a primeira travessia do Atlântico Sul, realizada pelo navegador Amyr Klink ${ }^{39}$. A partir de 1985 a empresa começa o fornecimento industrial de produtos para a venda para o consumidor final, e não mais apenas atendendo a merenda escolar e os restaurantes industriais. Em 1987 desenvolve a alimentação balanceada para o projeto de invernagem polar do navegador Amyr Klink. No início da década de 1990, em 1992, lança o CHONK, primeira barra de cereais fabricada no Brasil e esse foi o primeiro projeto brasileiro de desenvolvimento sustentável utilizando produtos da Amazônia e parte dos lucros com as vendas da barra de cereal era revertito para as comuidades carentes através do IPEA Instituto de Pesquisa e Estudos Amazônicos. Com a dificuldade na área de merendas escolares ${ }^{40}$, a partir de 1994 a Nutrimental investiu nesse produto pouco conhecido no mercado brasileiro e que foi desenvolvido para alguns esportistas: a barra de cereais. Era um nicho de mercado incipiente os consumidores preocupados com a saúde e alimentaçao balanceada. O CHONK muda de nome e

\footnotetext{
${ }^{39}$ O navegador brasileiro partiu da costa da Namíbia, na África, a bordo do Paraty, um barco de quase seis metros, para cumprir um dos maiores desafios já enfrentados por um navegador: cruzar sozinho o Atlântico Sul. Desde a partida na costa do continente africano até o litoral brasileiro foram 100 dias. IN: Há 30 anos, Amyr Klink fazia primeira travessia solitária a remo do Atlântico Sul. Disponível em http://www.amyrklink.com.br/ha-30-anos-amyr-klink-fazia-primeiratravessia-solitaria-a-remo-do-atlantico-sul/. Acesso 28.jan.2016 e http://www.amyrklink.com.br/amyr-klinkcomemora-os-30-anos-de-travessia-do-atlantico-em-barco-a-remo/. Acesso em 20.jan.2016.
}

${ }^{40}$ Em 1990, quando a Nutrimental enfrentou uma grave crise, Rodrigo da Rocha Loures inovou na gestão e investiu para transformar sua empresa numa organização de aprendizagem. A Nutrimental, que até então fornecia merenda escolar ao governo federal, com o envolvimento de todos os seus colaboradores reinventou seu negócio e passou a focar o mercado de consumo. A virada veio com ganhos extraordinários de produtividade e o lançamento de um produto inédito no país: a barra de cereais. Fonte: Presidente da Fiep faz conferência magna com o tema "Desafios de Ação e Empreendedorismo" na XXII Confam. 27 de agosto de 2010, disponível http://bpwbrasil.org/new/?p=259. Acesso 12.fev.2016. 
passa a se chamar NUTRY. Atualmente a empresa possue as marcas Nutry, Nutrilon, Nutribom, Nutrimental e Nutrinho e disponibiliza produtos de alimentação infanto-juvenil, barras de cereais e de frutas, bebidas sobremesas e preparações culinárias, além de desenvolver e produzir produtos para a indústria alimentícia ${ }^{41}$.

Com relação a expansão da sua unidade industrial ${ }^{42}$, na década de 1980 seu grupo já representava um complexo formado por 5 fábricas, empregando diversas tecnologias de ponta, com mais de dois mil colaboradores em vários estados brasileiros. Em 1977 abre uma filial em Guaramirim/SC que no início da década de 1990 chegou a contar com mais de 600 trabalhadores. Essa filial foi fechada em 2001 e não contava com mais de 70 trabalhadores na época. Os extrabalhadores dessa filial dispensados em 1992 entraram com uma ação trabalhista coletiva pedindo indenização por insalubridade e pericularidade. Depois de quase 16 anos, em 2008 a empresa deve que pagar o acordo judicial que na época ficou no valor final de um pouco mais de 2 milhões de reais ${ }^{43}$. Para entender o porque da morosidade da tratativa dessa ação judicial, temos que fazer uma retrospectiva histórica ao final da década de 1980: a Nutrimental foi uma das quatro empresas brasileiras investigadas por suspeita de superfaturamento nas licitações para venda de merenda escolar, em 1989, durante o governo Collor ${ }^{44}$. O contrato foi cancelado "e aí a empresa entrou em

\footnotetext{
${ }^{41}$ Chamada de Food Ingredients são vegetais e frutas desidratadas, entre outros mixes elaborados, para incrementar a linha de produtos das empresas alimentícias. Estes componentes contribuem com notas de odor, sabor e frescor e podem ser utilizados em um grande número de alimentos (como pães, biscoitos, massas, queijos, embutidos, sopas, molhos, etc).

42 A companhia tem centros de distribuição em São José dos Pinhais, São Paulo, Pernambuco e Minas Gerais, onde também fica a fábrica de farinhas infantis adquirida da holandesa Royal Numico em 2005. Apesar de a empresa ser vice-líder na área de cereais matinais, segmento em que ingressou em 2007 para enfrentar gigantes como Kellog e Nestlé, o foco de expansão, pelo menos no curto prazo, está mesmo nas barrinhas. A Nutrimental também exporta o produto para o Mercosul - a marca é líder no Uruguai -, além de farinhas para o continente africano. A companhia, no entanto, não revela os volumes. Disponível em http://www.gazetadopovo.com.br/economia/nutrimental-quer-competircontra-junk-food-b7a3m5x40v9xttc7iiqw81tfy. Acesso em 27.jan.2016.
}

${ }^{43}$ Os valores pagos parcialmente batem com um valor o qual a empresa recebeu da Prefeitura de São José dos Pinhais, pela desapropriação de um terreno, o qual estava contabilizado em $\mathrm{R} \$ 500$ mil e foi indenizado por $\mathrm{R} \$ 2,5$ milhões (exatamente na mesma época do acordo). Disponpivel http://guiabemparana.cim.br/imangens/publicidade_legal/050513. Acesso em 23.jan.2016.

44

Processo

019.973/1991-8.

Disponível

em

http://contas.tcu.gov.br/portaltextual/MostraDocumento?lnk=(019.973/1991-8). Acesso em 28.jan.16.

Em 201, Rodrigo Santos Rocha Loures foi candidato a vice-governador no estado do Paraná, pela chapa de Osmar Dias do PDT, na época coligada com o PT e apoiada por Collor. Disponível em http://fodel.blogspot.com.br/2010/09/sindicalista-e-revelacoes-bombasticas.html. Acesso 28.jan.2016. 
decadência", ${ }^{45}$ conforme Sérgio Eccel, presidente do Sindicato dos Trabalhadores da Alimentação em 2008, e continua: "em 1995 foi feito empréstimo no antigo Bamerindus e todo o dinheiro foi investido na matriz, em São José dos Pinhais/PR, tiraram daqui e levaram para lá". Em dezembro de 2001, com o fechamento da filial em Guaramirim, a empresa tenta renegociar a dívida o quanto foi possível, mas com a compra do Banco Bamerindus pelo HSBC, teve que entregar o prédio e terreno em Guaramirim, menos as máquinas. Sérgio Eccel recorda que "a fábrica foi depenada, não deixaram nem uma lâmpada fluorescente sequer lá dentro". A produção estava reduzida a 70 trabalhadores, todos indenizados e pagos com dois salários de gratificação. Em 2008, a Justiça mantinha a penhora da matriz da Nutrimental, em São José dos Pinhais ${ }^{46}$. Em 2002 os empresários José Dequêch Neto e Arno Aldrovandi, proprietários da Distribuidora de Alimentos Dequêch e da rede de postos de combustíveis Pérola, respectivamente, adquiriram num leilão do Banco Central, o terreno com 17 mil metros quadrados, prédios e os dez silos de armazenamento de grãos que pertenciam à Nutrimental no município de Guaramirim. Na época, o valor do imóvel e o montante da dívida não foram revelados, mas extraoficialmente, o valor do terreno e os prédios eram estimados em R \$ 7 milhões e os empresários adquiriram em leilão, por R \$ 1,9 milhão, o terreno e instalações da extinta unidade da Nutrimental ${ }^{47}$.

Com relação a crise que a Nutrimental passou no início dos anos 1990 e que quase a derrotou, Manfredini (2011) aponta que foi a ampla participação dos funcionários que ajudou na superação. O recém empossado Governo Fernando Collor de Mello desmantelou bruscamente os programas estatais de nutrição mantidos pelos ministérios da Educação e da Saúde, dos quais a Nutrimental era fornecedora. Além disso, a empresa deixou de receber parte do que lhe era devido pelo Governo Federal. "De uma hora para outra ficamos sem $70 \%$ do nosso mercado e, além disso, com dívidas", explica Rocha Loures (MANFREDINI, 2011, p.15). Foi aí que a empresa reposicionou seu negócio, passando a focar o mercado de consumo. E não sofreu mais sustos. Dez

\footnotetext{
45 Oliveira (2007, p.166) também aponta "uma das principais receitas da Nutrimental provinha da merenda pública, justamente na época em que Gilda Poli da Rocha Loures era Secretária da Educação do Estado, fato que motivou um processo no Tribunal de Contas da União".
}

46 Ex-trabalhadores da Nutrimental beneficiados depois de 16 anos (11 de março de 2008). Disponível em http://informaluta.blogspot.com.br/2008/03/ex-trabalhadores-da-nutrimental.html. Acesso 26.jan.2016.

47 BUENO, Ney (2002). Empresários adquirem sede da Nutrimental: José Dequêch Neto e Arno Aldrovandi compraram em leilão, por R\$ 1,9 milhão, o terreno e instalações da extinta unidade. Disponível em http://www1.an.com.br/anjaragua/2002/nov/29/index.html. Acesso em 26.jan.2016. 
anos depois seria eleita pela revista Exame uma das cem melhores empresas para se trabalhar no Brasil. Portanto, temos dois pontos de vistas sobre o governo Collor e a questão da merenda escolar: a do ex-presidente do do Sindicato dos Trabalhadores da Alimentação de Guaramim e a do presidente-fundador da empresa, que merecem estudos mais aprofundados para se chegar a uma consideração final, mas que não cabe ao escopo desse artigo.

Em 1986 inaugura o centro de distribuição em Igarassú/PE ainda em funcionamento (REISSMANN, 2005)

Em agosto de 2005 comprou a unidade fabril de farinhas infantis da empresa Support que pertencia à holandesa Royal Numico e possuía planta na cidade mineira de Arceburgo. A partir da sua instalação em Minas Gerais, a Nutrimental passou a absorver 20\% do mercado de farinhas infantis, que é liderado pela Nestlé. Na unidade de Arceburgo é produzido as marcas de farinhas infantis Nutrilon, Nutriton, Nutron e Farinha Láctea Nutrimental. ${ }^{48}$

Hoje, a empresa Nutrimental é líder no mercado nacional de barras de cereais e vice-líder em cereais infantis. Possui duas unidades fabris: São José dos Pinhais/PR e Arceburgo/MG ${ }^{49}$, emprega mais de mil funcionários e possui um faturamento anual na casa dos $\mathrm{R} \$ 270$ milhões (MANFREDINI, 2011, p.15)

\section{CONSIDERAÇÕES FINAIS}

A família Rocha Loures está presente no poder político e econômico da região desde a época da fundação da cidade, há mais de trezentos anos. Rodrigo Santos da Rocha Loures, grande empresário, filho de Rodrigo Costa da Rocha Loures, uma das maiores lideranças empresariais do Paraná e Diretor da Nutrimental, em seu discurso de lançamento da candidatura a deputado federal, em 2005 diz:

\footnotetext{
${ }^{48}$ A empresa de alimentos Nutrimental Ltda fechou 2006 com faturamento de $\mathrm{R} \$ 228$ milhões, o que representou um crescimento de $30 \%$ em relação a 2005. Disponível em http://www.paginarural.com.br/noticia/55196/minas-geraisimpulsiona-negocios-da-nutrimental. Acesso 12.fev.2016.

${ }^{49}$ Disponível em http://www.nutrimental.com.br/. Acesso 12.fev.2016.
} 
Quero servir ao Paraná! Quero servir ao governador Requião! Sou bisneto, neto e filho de uma dinastia que serve ao Paraná! Do alto da pirâmide milionária da FIEP nos contemplam 500 anos de fome, subdesenvolvimento e analfabetismo político ${ }^{50}$.

Seguindo as orientações de Oliveira (2007, p.169), essa declaração é expressiva das redes sociais e de parentesco que se tramam em torno do poder. A atuação da família Rocha Loures é um exemplo da continuidade dos donos do poder, que possui ramificações de mais de trezentos anos. "Eles ilustram o princípio da reprodução e, por vezes, da conciliação, que permite a manutenção de carreiras políticas e estruturas de poder, independentemente dos regimes políticos, das diferentes composições partidárias e políticas e dos ciclos econômicos. As múltiplas conexões entre poder econômico, poder político e estruturas de parentesco estão sempre sendo renovadas e estão em constante movimento".

Numa das redes mais fortes de poder político e parentesco ${ }^{51}$, os Rocha Loures mantêm-se até os dias atuais no poder. Sucesso esse garantido pela junção do poder econômico com as relações sociais com figuras da mais alta elite política tradicional do Paraná. O trânsito da família Rocha Loures pelas elites e suas relações políticas, de parentesco e de poderio econômico faz com que a família garanta a colocação de parentes e correligionários em cargos estratégicos.

„,, numa época em que o nepotismo era forma político administrativa usual, os membros da família estavam bem colocados profissionalmente, sendo que alguns ocupavam cargos de relevo. (PIERUCCINI, 1996, p. 98)

Os estudos tradicionais tendem a considerar a influência do parentesco reduzido nas sociedades complexas, destacando a sua função primária de reprodução e unidade produtiva, a família nuclear, o que impede a compreensão de como a família é moldada por outros meios como as redes políticas e econômicas. Estudos mais recentes como Oliveira $(2001,2007)$ demonstram

\footnotetext{
50 Disponível em http://www.jornaldoestado.com.br/ze_beto/index.php?archives=Julho-2006\&in=20. Acesso 14.fev.2016

51 "Em mais um casamento promissor para a rede política da família Rocha Loures, uma das netas de João Alves da Rocha Loures, filha de Ruy Costa da Rocha Loures e Ruth Dalcól, por consequência sobrinha de Rodrigo e prima de Rodriguinho Rocha Loures, a nutricionista Simone Rocha Loures Braga Cortes é esposa de Felipe Braga Cortes, vereador em Curitiba por quatro mandatos, filho do ex-Deputado Federal Fabiano Braga Cortes e sobrinho do exgovernador Ney Braga" (SILVA, 2015a, p.165).
} 
essa outra dimensão da família, procurando revelar as interpenetrações e as incorporações de instrumentos e regras legais que convertem-na para um dimensão mais integral baseada no parentesco como rede de sustentação. Essas interpenetrações desafiam as perspectivas que consideram o parentesco reduzido nas sociedades complexas demonstrando que nas sociedades contemporâneas ele está presente, como item fundamental, nos universos individualistas como a liberdade individual e na escolha.

A estruturação de empresas em torno de laços familiares é considerada uma condenação ao fracasso pelos estudos tradicionais, mas podemos perceber pela breve análise da família Rocha Loures como o espirito patricarcal e as tendências clânicas não se restringem ao ambiente familiar, mas atingem as empresas, o mundo dos negócios.

A visão schumpeteriana do empresário capitalista para o qual a inovação é a fonte básica de lucro deve ser associada com as famílias empresariais, a organização em moldes impessoais e formais parecem não atingir a eficiência quando falamos de Brasil. Nas palavras do empresário Rodrigo Costa da Rocha Loures:

Revista: O senhor fala frequentemente em "prosperidade sustentável", uma proposta de gestão, um empreendedorismo que respeite os atributos e características da cultura brasileira. O que é isso?

Rodrigo Costa: Os modelos e teorias de gestão importados - sobretudo os norte-americanos - partem do pressuposto de que o que funciona numa empresa é a estrutura hierárquica e sua cadeia de chefias. Com o tempo percebi que, diferentemente, nossa cultura valoriza as relações pessoais, sendo a cooperação entre elas - isto é, o capital social - o elemento chave para o sucesso da empresa. Quando tivemos que fazer uma reinvenção da Nutrimental, no início dos anos 90, no contexto de uma crise que ameaçava a empresa de desaparecer, o decisivo foi o engajamento dos colaboradores e o fato de termos confiado que as escolhas que eles faziam eram acertadas. (MANFREDINI, 2011, p.13)

Em suma, o capital, não apenas o monetário, mas em suas outras variantes tão bem desenvolvida na teoria de Pierre Bourdieu - capital social, cultural, simbólico e político - marcam a atuação dessas famílias históricas e políticas da história paranaense. A família Rocha Loures é um exemplo de OLD MONEY, ou seja, exemplo de uma riqueza herdada de famílias de classe alta já estabelecidas, seus membros são pessoas pertencentes a uma família ou linhagem possuidora de 
riqueza herdada. Esse termo geralmente descreve uma classe de ricos que têm sido capazes de manter sua riqueza ao longo de várias gerações ${ }^{52}$ (ALDRICH, 1996).

Mas há ainda várias questões que precisam ser levantadas e respondidas, como por exemplo, qual a lógica e segredos das famílias empresariais? O que há por trás da acumulação primitiva? O que é expropriado para garantir as grandes riquezas? Nos estudos de trajetórias e itinerários a versão que destaca o mérito é sempre a história autorizada, mas e a versão que reflete o lado social e político dessas famílias empresariais: será que teriam conseguido suas fortuns e não tivessem a estrutura do Estado a seu favor? É possível ser um grande empresário sem a redoma política para a sua sustentação? Quais são os mecanismos corporativos empresariais de hoje? Conforme Oliveira (2010, p.1) "o estudo dos ricos e poderosos é o estudo de uma estrutura social formada na longa duração. $\quad . . . \quad$ o estudo dos ricos e poderosos é uma investigação histórica sobre famílias e estruturas de parentesco".

\section{REFERÊNCIAS}

ALDRICH, Nelson (1996). Old money: the mythology of wealth. Allworth Press.

BATISTElla, Alessandro (2014). O Partido Trabalhista Brasileiro no Paraná (1945-1965). Porto Alegre: Doutorado História/UFRGS.

BOURDIEU, Pierre (1980). Le sens pratique. Paris: Editions Minuit.

COHEN, Abner (1981). The politics of elite culture: explorations in the dramaturgy os power in a modern African society. Berkley: University of California Press.

GRANATO, Natália Cristina (2013). PTB, Ministério do Trabalho e governo João Goulart: a trajetória política do trabalhista paranaense Amaury de Oliveira e Silva. Curitiba: Monografia conclusão de curso de Ciências Sociais/UFPR

MARCUS, George (1992). Lives in trust: the fortunes os dinastic families in late Twentieth century America. San Francisco/Oxfor: Westiview Press.

\footnotetext{
${ }^{52}$ Old Money contrasta com os novos ricos. Estes caem sob a categoria "dinheiro novo", ou seja, aqueles que não são de famílias tradicionalmente ricas. O termo Old Money também se aplica aos das classes altas cuja riqueza os separa de classes mais baixas (ALDRICH, 1996).
} 
MANFREDINI, Luiz Alberto Amaral (2011). "Rodrigo Rocha Loures: a indústria no centro do desenvolvimento”. IN: Empreendedores do Paraná: volume 4. Curitiba: FIEP/SENAI-DR/SESIDR, p.10-15.

NEGRÃO, Francisco (1928). Genealogia Paranaense (volumes 1 ao 6). Curitiba: Imprensa Oficial.

NICOLAS, Maria (1984). 130 anos de vida parlamentar paranaense (1854-1984). Curitiba: ALEP.

NICOLAS, Maria (1977). O Paraná na Câmara dos Deputados (1853-1977). Curitiba: Academia Paranaense de Letras.

OLIVEIRA, Ricardo Costa de (2007). Famílias, poder e riqueza: redes políticas no Paraná em 2007. IN: Sociologias, N.18. Porto Alegre Julho/Dezembro.

OLIVEIRA, Ricardo (2010). A Longa Duração da Riqueza e do Poder no Brasil. Disponível em file:///C:/Users/User/Downloads/A_Longa_Duracao_da_Riqueza_e_do_Poder_no.pdf. Acesso em 28.fev.2016.

OLIVEIRA, Ricardo Costa de (2012). Na teia do nepotismo. Curitiba: Insight.

OLIVEIRA, Ricardo Costa de (2001). O silêncio dos vencedores: genealogia, classe dominante e Estado no Paraná. Curitiba: Moinho de Vento.

OLIVEIRA, Ricardo Costa de (2016). Entrevista concedida à Ana Vanali em 04 de junho de 2016.

PISCITELLI, Adriana (1999). Joias de família: gênero em histórias sobre grupos empresariais brasileiros. Campinas: Tese de doutorado em Antropologia UNICAMP.

REISSMANN, Carlos Rodolfo (2005). Estratégias de diferenciação no mercado internacional de alimentos: estudo de caso da rastreabilidade do "Nutry" pela Nutrimental S.A. Curitiba: Mestrado em Administração/UFPR.

RESENDE, Daiane Carnelos (2014). Elementos decisivos na construção da posição e ação política de Roberto Requião de Mello e Silva. Jundiaí: Paco Editorial.

ROMAGUERA NETTO, Luiz (1992). Gertrudes e o Padre Camargo: genealogia paranaense. Curitiba: edição do autor.

SILVA, Carla Andréia Alves da (2015). Poder político e relações de parentesco no município de Londrina-Paraná. IN: REVISTA NEP (Núcleo de Estudos Paranaenses) Curitiba, v.1, n.1, p. 203223, dezembro. 
SILVA, Carla Andréia Alves da (2015a). Poder político e relações de parentesco no município de Londrina-Paraná. Curitiba: dissertação mestrado Sociologia/UPFR.

TAKATUZI, Tatiana (2014). Águas batismais e santos óleos: uma trajetória histórica do Aldeamento Atalaia. Curitiba: SAMP.

TEIXEIRA, Murilo Walter (2009). Genealogia do Capitão Rocha (Antonio da Rocha Loures). Guarapuava: edição do autor.

THOMÉ, Nilson (2002). A política no Contestado: do curral da fazenda ao pátio da fábrica (primeiro estudo sobre a formação política da Região do Contestado a reboque das oligarquias tradicionais de Santa Catarina. Do coronelismo ao neocoronelismo - 1881/1970). Caçador: UNC

YANAGISAKO, Silvia (1991). Capital and gendered interest in Italian Family firms. IN: KERTZER, David e SALLER, Richard (eds). The Family in Italy: from antiquity to the present. New Haven/London: Yale University Press.

WENDLAND, Daniely (2011). Integralismo, círculo operário católico e sindicatos em Joinville (1931-1948). Florianópolis: Mestrado em História/UFSC.

\section{Notícias na internet}

AGÊNCIA FIEP (2006). Nota de falecimento de Rachel da Costa Rocha Loures. http://www.agenciafiep.com.br/noticia/nota-de-falecimento/. Acesso em 10.jan.2016.

MEMÓRIA IAP. João Alves da Rocha Loures. Disponível em http://www.iappr.org.br/memoria/1937/. Acesso em 10.jan.2016.

O TROPEÇO DOS $\quad$ LOURES. $\quad$ Disponível em http://www.blogdobronca.com.br/noticia.php?id=4314. Acesso 10.jan.2016.

PEDROSO, Luis Renato (2004). A doce e venerável dama. Disponível em http://www.paranaonline.com.br/canal/opiniao/news/97119/. Acesso em 10.jan.2016.

Perfil: Rodrigo Costa da Rocha Loures, presidente do Conic da Fiesp. Disponível em http://www.fiesp.com.br/noticias/perfil-rodrigo-costa-da-rocha-loures-presidente-do-conic-dafiesp/. Acesso em 10.jan.2016.

Indústria paranaense utiliza estratégias inovadoras para superar crises e se manter competitiva. Disponível http://www.unifae.br/publicacoes/pdf/revista_fae business/n2_junho_2002/ambiente economico4 nutrimentalSA.pdf. Acesso em 10.jan.2016. 
Dona da barrinha Nutry quer ampliar mercado com novas linhas. Revista Exame (Editora Abril). Disponível em http://exame.abril.com.br/negocios/noticias/dona-da-barrinha-nutry-quer-ampliarmercado-com-novas-linhas. Acesso em 10.jan.2016.

MEMÓRIA IAP - João Alves da Rocha Loures. Disponível em http://www.iappr.org.br/memoria/1937/. Acesso 27.fev.2016.

\section{AN EXAMPLE OF OLD MONEY IN PARANÁ: FAMILY ROCHA} LOURES

\section{ABSTRACT}

The family Rocha Loures, with wide circulation among the ruling elites since the seventeenth century, combines economic power to political power. One of the family members got more prominence and political influence: Rodrigo Costa da Rocha Loures, food industry entrepreneur and founder of Nutrimental, the paper analyzes the importance of Rocha Loures family for the economy and Paraná state politics.

Key-words: Rocha Loures. Nutrimental. Family and economy. Paranaenses companies. 